\title{
A novel control-rod drive mechanism via electromagnetic levitation in MNSR
}

\author{
Mohammad Divandari, \\ Mehdi Hashemi-Tilehnoee, \\ Masoud Khaleghi, \\ Mohammadreza Hosseinkhah
}

\begin{abstract}
In this paper, an electromagnetic levitation system was used with a synchronous motor to navigate the control rod of a small-type research reactor. The result from this prototype magnetic levitation system was in agreement with simulation results. The control system was programmed in MATLAB through open-loop system, closed-loop with state feedback and closed-loop with state feedback integral tracking. The final control system showed the highest performance with a low positioning error. Our results showed that the developed control system has the potential to be used as a reliable actuator in nuclear reactors to satisfy higher performance and safety.
\end{abstract}

Key words: magnetic levitation system $\bullet$ nuclear reactor $\bullet$ state feedback $\bullet$ tracking

M. Divandari, M. Hashemi-Tilehnoee ${ }^{\bowtie}$, M. Hosseinkhah Department of Electrical Engineering,

Aliabad Katoul branch, Islamic Azad University,

Aliabad Katoul, Iran,

Tel.: +98911353 2381,

E-mail: mehdi.hashemi.t@gmail.com

\section{Khaleghi}

Department of Mechanical Engineering,

Sirjan University of Technology,

Kerman, Iran

Received: 17 December 2013

Accepted: 25 April 2014

\section{Introduction}

The control-rod (CR) driving mechanism is one of the most important safety equipment that controls important functions such as the start, power adjustment and shutdown of the reactor.

The hydraulic control-rod driving system was specifically developed for the nuclear heating reactor (NHR). A similar CR driving mechanism had been operated in the 5 MW experimental NHR (NHR-5), since 1989. This system has a hydrodynamic pressure driving mechanism, which uses the reactor coolant (water) as a working medium. The commercial sized NHR with an output of 200 MWT (NHR-200), which has been developed by INET is one of the last nuclear heating reactors [1]. Yuanqiang et al. [2] tested the $10 \mathrm{MW}$ high temperature gas-cooled reactor-test module (HTR-10) control-rod system. The control-rod system of the HTR-10 was designed to work at high temperature, high radiation and in helium environment. The stepping motor as the motive power source contributes to simplify the control-rod driving mechanism because of omission of the traditional brake clutch counterweight. The sprocket wheel device, an actuator of the control rod, is more suitable for the HTR-10 than other possible designs. A magnetic damper, a kind of the deceleration-device based on the electromagnetic principle was used to limit the emergency insertion speed of the control rod [2].

The high-temperature engineering test reactor (HTTR) control rods is individually suspended by support cables from the control-rod drive mechanisms, and are driven by using the alternating current motor. On the contrary, the electromagnetic clutch is separated to insert the control rods into the reactor core by gravity 
when electric current through the clutch is cut off by a reactor scram signal [3].

Chyou et al. [4] presented a case study of prototyping a control-rod driving mechanism (CRDM) in the Taiwan Research Reactor (TRR-II). Two major components, the movable magnetic coils and the hydraulic damper, were studied as paradigms to envisage the indispensable role of experimental mechanics in the prototyping of CRDM. The former is responsible for the position adjustment of the control rod during normal operation, while the latter provides the damping mechanism needed to subdue the ultimate impact of the CRDM during scram condition and preserve its mechanical integrity. Experimental data in various aspects confirm that the prototype has fulfilled the specifications.

In 2010, Shirazi et al. [5] proposed a simple design and implementation of a microcontroller-based system for the automatic movement of control rods in nuclear reactors. The processes of this system have been simulated in MAT-
$\mathrm{LAB}$ and all responses of the system, including oscillation and transient responses, analyzed. But, the authors did not analyze the real conditions of a control-rod driving mechanism as a function of mass, velocity and time. This system can be used for educational purposes.

In 2008, Tanaka et al. [6] developed a 3-D virtual analysis system to analyze the motion of CRDM. The analysis system consists of a 3-D model to calculate the forces acting on the mechanism, and was verified by mock-up test. The 3-D simulator was verified by mock-up test to accurately simulate the CRDM motion including its sensitivity against variable parameters. The analysis system is useful for functional evaluation in maintenance or to factor out root causes for malfunction of CRDM.

Malfunction of CRDM and originated accidents have been discussed in different works. In 2012, the RELAP5 Mod3.2 code has been used to analyze the rod ejection accident (REA) in a VVER-1000 reactor. A 58-mm break

Table 1. Technical specifications of the MNSR facility [7]

\begin{tabular}{|c|c|c|}
\hline & Parameter & Description \\
\hline Plant & $\begin{array}{c}\text { Reactor type } \\
\text { Thermal power } \\
\text { Cooling system } \\
\text { Internal irradiation channels } \\
\text { External irradiation channels }\end{array}$ & $\begin{array}{c}\text { Tank-in-pool } \\
30 \mathrm{~kW} \\
\text { Natural convection } \\
5 \\
5\end{array}$ \\
\hline $\begin{array}{l}\text { Maximum thermal neutron fluxes } \\
\text { and temperature in irradiation sites }\end{array}$ & $\begin{array}{l}\text { Inner sites } \\
\text { Outer sites }\end{array}$ & $\begin{array}{l}1 \times 10^{12} \mathrm{n} \cdot \mathrm{cm}^{-2} \mathrm{~s}^{-1},<45^{\circ} \mathrm{C} \\
5 \times 10^{11} \mathrm{n} \cdot \mathrm{cm}^{-2} \mathrm{~s}^{-1},<36^{\circ} \mathrm{C}\end{array}$ \\
\hline Fuel element & $\begin{array}{c}\text { Fuel } \\
\text { Enrichment } \\
\text { Fuel density } \\
\text { Diameter of fuel pellet } \\
\text { Clad material } \\
\text { Clad thickness } \\
\text { Fuel pin total length } \\
\text { Fuel pin active length } \\
\text { Diameter of fuel rod }\end{array}$ & $\begin{array}{c}\mathrm{UAl}_{4} \text { dispersed in } \mathrm{Al} \\
90.2 \% \\
3.456 \mathrm{~g} / \mathrm{cm}^{3} \\
4.3 \mathrm{~mm} \\
\mathrm{Al}-303 \\
0.60 \mathrm{~mm} \\
250 \mathrm{~mm} \\
230 \mathrm{~mm} \\
0.55 \mathrm{~cm}\end{array}$ \\
\hline Core & $\begin{array}{c}\text { Core geometry } \\
\text { Core diameter } \\
\text { Core height } \\
\text { Number of concentric circles on the grid } \\
\text { Number of fuel rod position } \\
\text { Number of fuel rods loaded } \\
\text { Number of dummy rods } \\
\text { Excess reactivity } \\
\text { Temperature coefficient }\end{array}$ & $\begin{array}{l}\text { Cubic cylindrical } \\
230 \mathrm{~mm} \\
230 \mathrm{~mm} \\
10 \\
354 \\
343 \\
7 \\
3.85 \mathrm{mk} \\
-0.1 \mathrm{mk} /{ }^{\circ} \mathrm{C}\end{array}$ \\
\hline $\begin{array}{l}\text { Results of excess reactivity } \\
\text { transient }\end{array}$ & $\begin{array}{c}\text { Peak power } \\
\text { Time to peak } \\
\text { Outlet coolant temperature } \\
\text { Maximum wall temperature of fuel element } \\
\text { Radiation dose rate }\end{array}$ & $\begin{array}{c}76 \mathrm{~kW} \\
360 \mathrm{~s} \\
62^{\circ} \mathrm{C} \\
92^{\circ} \mathrm{C} \\
<0.2 \mathrm{mRem} / \mathrm{h}\end{array}$ \\
\hline Control rod & $\begin{array}{c}\text { Number of control rods } \\
\text { Absorber material } \\
\text { Control-rod diameter including S.S. tube } \\
\text { Control-rod travel length }\end{array}$ & $\begin{array}{l}1 \\
\text { Cadmium } \\
5 \mathrm{~mm} \\
230 \mathrm{~mm}\end{array}$ \\
\hline Reflectors & $\begin{array}{c}\text { Material } \\
\text { Side reflector } \\
\text { Bottom reflector } \\
\text { Top reflector } \\
\end{array}$ & $\begin{array}{l}\text { Metallic beryllium } \\
10.2-\mathrm{cm} \text { thick } \\
5.1-\mathrm{cm} \text { thick } \\
\text { Variable thickness } \\
\end{array}$ \\
\hline
\end{tabular}


is considered in the upper head of the reactor pressure vessel due to the impact of an ejected rod. The results of the RELAP5 code in different operating condition are consistent with VVER-1000 FSAR data [8].

In this paper, the CRDM of a research reactor is studied. In the first step, the in-use drive mechanism act on the rod using electric motor and rod will be moved at starting position. Then, an auxiliary drive mechanism via magnetic levitation system will control the rod position. Non-linear differential equations with an electrical excitation mechanism have been proposed. These equations linearize around an equilibrium point. A state feedback control with integral tracking for stability and improvement of the position error has been used.

\section{Reactor description}

The miniature neutron source reactor (MNSR), developed by the Chinese Institute of Atomic Energy, is a compact research reactor based on the Canadian SLOWPOKE reactor design. The MNSR is a low power tank-in-pool type research reactor and uses highly enriched uranium as fuel, light water as a moderator and coolant, and metallic beryllium as a reflector. Technical specifications of MNSR reactor are summarized in Table 1.

The core of the MNSR consists of the fuel cage, one central control rod and its guide tube, fuel pins (fuel rods), dummy rods and tie rods, with the generated heat removed through natural circulation.

The water and fuel temperatures rise during the reactor daily operational time, which is about $2.5 \mathrm{~h}$. The water temperature increases from $20^{\circ} \mathrm{C}$ to $45^{\circ} \mathrm{C}$ and the fuel temperature increases from $20^{\circ} \mathrm{C}$ to $65^{\circ} \mathrm{C}$. MNSR includes one central rod, cadmium absorber and stainless steel as cladding, so that the total reactivity worth of the control rod is only $7 \mathrm{mk}$. Thus, a small neutron flux variation is found near the control $\operatorname{rod}(\approx 5 \mathrm{~cm}$ far from the rod).

\section{Methodology}

The MNSR has two modes of control system, the manual and the automatic. One is an operator's control system, where the neutron flux level can be kept in a given band and another is a computer closed-loop control system which satisfies the stable neutron flux. Because the control system for the MNSR consists of only one control rod, the system for its control is correspondingly simple. To detect the reactor characteristics and to test the instrumentations, the $\mathrm{BF}_{3}$ ion chambers, small fission type neutron chamber and Gamma-chamber, self-powered cobalt detector, water temperature detectors of thermocouple type for inlet, outlet and difference and radiation detectors, are located in irradiation sites near the core, or outside the reactor vessel. As we know, often last drive mechanisms were just electric motor, but in this method a new mechanism by electromagnetic levitation system (EMLS) has been proposed. Figure 1 shows the MNSR with EMLS.

The control scheme which consists of the computer, operating data acquisition system and executive body is shown in Fig. 2.

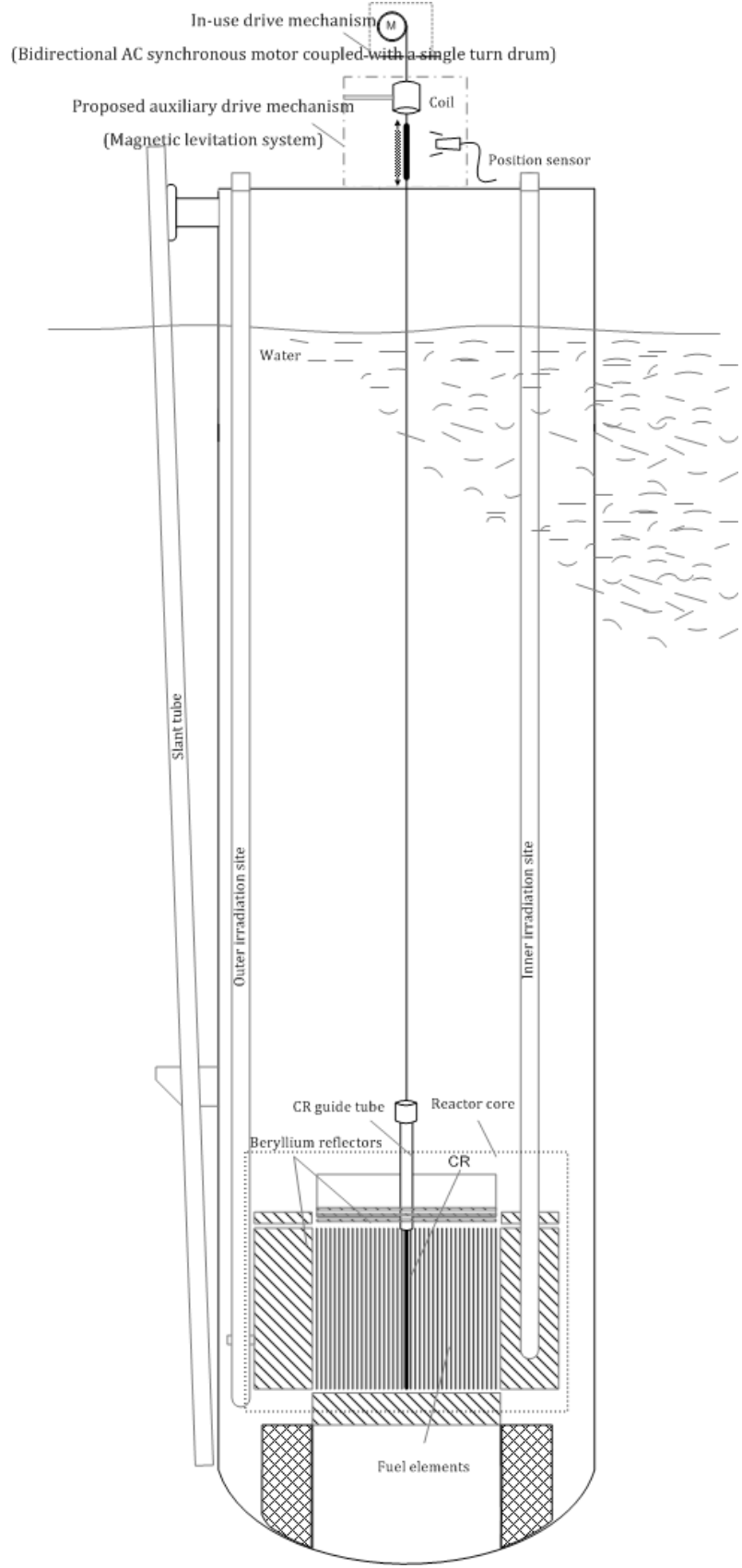

Fig. 1. MNSR with EMLS.

\section{Magnetic levitation system}

The basics of an EMLS for rod position control is shown in Fig. 3. It can be seen that the magnetic force, $i^{2} / y$, is opposite to gravity of the levitated steel shaft. The magnetic force $C \cdot i^{2} / y$ ( $C$ factor is 1$)$ depends on the electromagnet current $i$, electromagnet characteristics and air gap $y$ between the steel hollow shaft and the electromagnet $[9,10]$.

Motion equation of the hollow steel shaft can be expressed by the following equation:

$$
\begin{gathered}
M \cdot \frac{d^{2} y(t)}{d t^{2}}=M g-\frac{i^{2}}{y(t)} \\
U(t)=R . i(t)+L \frac{d i}{d t}
\end{gathered}
$$




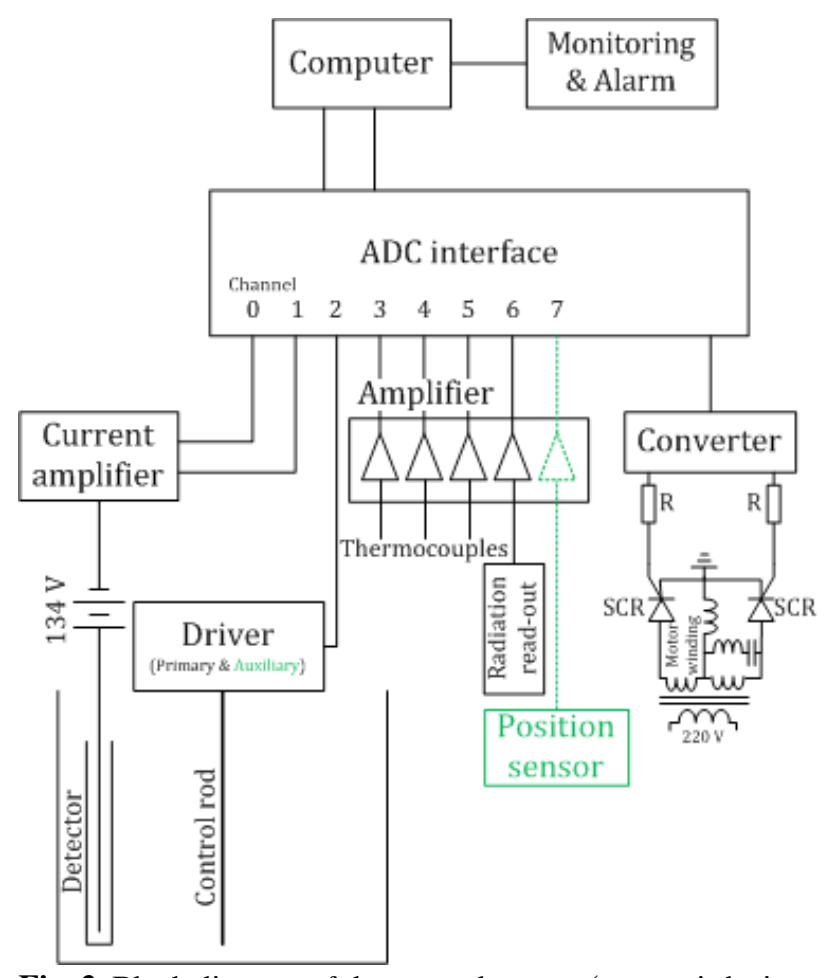

Fig. 2. Block diagram of the control system (magnetic levitation control --- ).

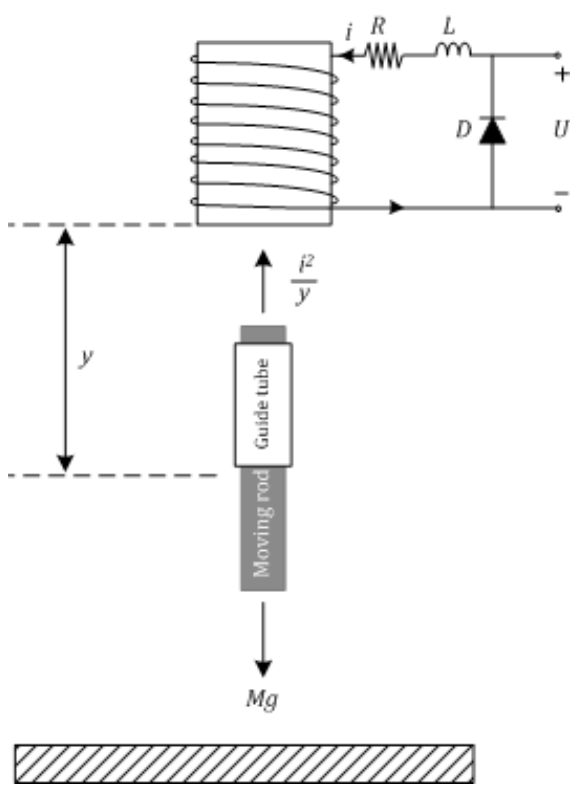

Fig. 3. The basics of an electromagnetic levitation system.

Choosing the states $x_{1}(t)=y(t), x_{2}(t)=[(d y(t)) / d t]$, and $x_{3}(t)=i(t)$ and Eqs. (1) and (2), state space equations described as follows,

$$
\begin{gathered}
\frac{d x_{1}}{d t}=x_{2}(t) \\
\frac{d x_{2}}{d t}=g-\frac{1}{M} \frac{x_{3}^{2}(t)}{x_{1}(t)} \\
\frac{d x_{3}}{d t}=\frac{R}{L} x^{3}(t)-\frac{1}{L} U(t) \\
\mathrm{X}(t)=\left[\begin{array}{lll}
x_{1}(t) & x_{2}(t) & x_{3}(t)
\end{array}\right]^{\mathrm{T}}
\end{gathered}
$$

where, $\mathrm{X}(t)$ is state vector, and initial conditions are:

$$
\begin{gathered}
y_{0}(t)=x_{01}=\text { const. } \\
x_{02}(t)=\frac{d x_{01}}{d t}=0 \\
\frac{d^{2} y_{0}(t)}{d t^{2}}=0 \\
i_{0}(t)=x_{03}(t)=\sqrt{M g x_{01}}
\end{gathered}
$$

Finally, the system matrix, input matrix and output matrix of the reactor control-rod position with magnetic levitation system expressed as:

$$
\begin{aligned}
& \mathrm{A}^{*}=\left[\begin{array}{ccc}
0 & 1 & 0 \\
\frac{x_{03}}{M \cdot x_{01}{ }^{2}} & 0 & \frac{-2 x_{03}}{M \cdot x_{01}} \\
0 & 0 & \frac{-R}{L}
\end{array}\right]=\left[\begin{array}{ccc}
0 & 1 & 0 \\
\frac{g}{x_{01}} & 0 & \left(\frac{g}{M \cdot x_{01}}\right)^{\frac{1}{2}} \\
0 & 0 & \frac{-R}{L}
\end{array}\right] \\
& \mathrm{B}^{*}=\left[\begin{array}{lll}
0 & 0 & \frac{1}{L}
\end{array}\right]^{T}, \quad \mathrm{C}^{*}=\left[\begin{array}{lll}
1 & 0 & 0
\end{array}\right]
\end{aligned}
$$

where, open-loop poles are placed in

$$
\left|s . I-\mathrm{A}^{*}\right|=0
$$

\section{Rod position control}

As mentioned before, the aim of the study is the design of control-rod position control that yields desirable closed-loop performance under steady-state and transient conditions. As we know, the open-loop poles (Eq. (12)) are controllable, i.e. controllability matrix is a full rank matrix, and then an arbitrary closed-loop eigenvalue placement via state-space feedback can be achieved.

\section{State feedback control law}

The open-loop system under study $\left(\mathrm{A}^{*}, \mathrm{~B}^{*}, \mathrm{C}^{*}\right)$ is represented by the LTI state space representation:

$$
\begin{aligned}
& \dot{\mathrm{X}}(t)=\mathrm{A}^{*} \cdot \mathrm{X}(t)+\mathrm{B} * \cdot U(t) \\
& \mathrm{Y}(t)=\mathrm{C}^{*} \cdot \mathrm{X}(t)+\mathrm{D}^{*} \cdot U(t)
\end{aligned}
$$

where direct matrix $\mathrm{D}^{*}$ is zero, the state feedback control law is:

$$
U(t)=-\mathrm{K} \cdot \mathrm{X}(t)+r(t)
$$

when $\mathrm{K}$ is the constant state feedback gain matrix then yields the closed-loop state equation with the desired performance characteristics. Block diagram of the state feedback control is shown in Fig. 4.

The closed-loop system dynamic matrix is expressed 


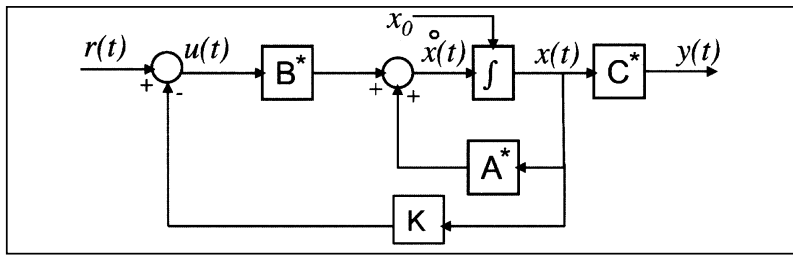

Fig. 4. Block diagram of the state feedback control.

$$
\begin{gathered}
\dot{\mathrm{X}}(t)=(\mathrm{A} *-\mathrm{B} * \cdot \mathrm{K}) \cdot \mathrm{X}(t)+\mathrm{B} * \cdot r(t) \\
\mathrm{Y}(t)=\mathrm{C}^{*} \cdot \mathrm{X}(t)
\end{gathered}
$$

The open-loop characteristic polynomial written as:

$$
\left|s I-\mathrm{A}^{*}\right|=s^{3}+a_{2} s^{2}+a_{1} s+a_{0}
$$

and closed-loop is:

$$
\left|s I-\mathrm{A}^{*}+\mathrm{B}^{*} \cdot \mathrm{K}\right|=\left(s+p_{1}\right) \cdot\left(s+p_{2}\right) \cdot\left(s+p_{3}\right)
$$

By closed-loop pole placement choosing the $p_{1}, p_{2}$, $p_{3}$, the gain matrix $\mathrm{K}$ is calculated to a feedback gain vector denoted by:

$$
\mathrm{K}=\left[k_{1}, k_{2}, k_{3}\right]
$$

The stability of closed-loop is the main target of control, but the tracking position error must be zero. Static pre-compensator will be obtained by $s=0$, $G(0)=-\left[C^{*}\left(A^{*}-B^{*} K\right)^{-1} B^{*}\right]^{-1}$. Since the input noise and measured noise always exist in the control system, try to dynamically compensate them by the tracking method [11].

\section{State feedback tracking}

Figure 5 shows the block diagram of the state feedback tracking control. Tracking error will be decreased using integral control even with noise.

The new control-law proposed is:

$$
U(t)=-\mathrm{K} \cdot \mathrm{X}(t)+k_{i} \cdot \xi(t)
$$

where,

$$
\dot{\xi}(t)=r(t)-y(t)
$$

in which $r(t)$ is the input (step position) reference to be tracked by $y(t), \xi(t)$ represents the integral of the tracking error. The Laplace transform of $\xi(t)$ with zero initial conditions gives:

$$
s \xi(s)=R(s)-Y(s)=E(s) \Rightarrow \xi(s)=\frac{E(s)}{s}
$$

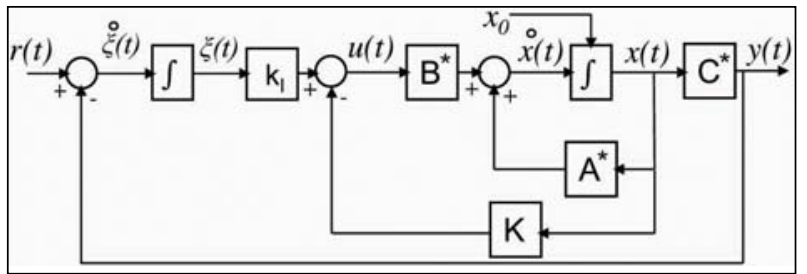

Fig. 5. Block diagram of the state feedback tracking control.
The control law can be written as:

$$
U(t)=-\left[\begin{array}{ll}
\mathrm{K} & k_{i}
\end{array}\right] \cdot\left[\begin{array}{l}
x(t) \\
\xi(t)
\end{array}\right]
$$

which can be expressed as a state feedback control law involving four-dimensional augmented state vectors formed by the open-loop state vector $x(t)$ and the integrator state variable $\xi(t)$. So, the new four-dimensional closed-loop state equations are:

$$
\begin{aligned}
& {\left[\begin{array}{l}
x(t) \\
\xi(t)
\end{array}\right]=\left[\begin{array}{lc}
\mathrm{A}^{*}-\mathrm{B}^{*} \cdot \mathrm{K} & \mathrm{B}^{*} \cdot k_{i} \\
\mathrm{C}^{*} & 0
\end{array}\right] \cdot\left[\begin{array}{l}
x(t) \\
\xi(t)
\end{array}\right] \cdot\left[\begin{array}{l}
0 \\
1
\end{array}\right] \cdot r(t)} \\
& y(t)=-\left[\mathrm{C}^{*} \quad 0\right] \cdot\left[\begin{array}{l}
x(t) \\
\xi(t)
\end{array}\right]
\end{aligned}
$$

Closed-loop system response is determined by the eigenvalues of the $\left[x_{1}, x_{2}, x_{3}, \xi\right]^{\mathrm{T}}$ closed-loop system dynamic matrixes:

$$
\left[\begin{array}{lc}
\mathrm{A}^{*}-\mathrm{B}^{*} . \mathrm{K} & \mathrm{B}^{*} \cdot k_{i} \\
-\mathrm{C}^{*} & 0
\end{array}\right]=\left[\begin{array}{cc}
\mathrm{A} & \mathrm{B} \\
-\mathrm{C} & 0
\end{array}\right]-\left[\begin{array}{l}
\mathrm{B} \\
0
\end{array}\right] \cdot\left[\begin{array}{ll}
\mathrm{K} & k_{i}
\end{array}\right]
$$

It can be proved that the arbitrary placement of the closed-loop eigenvalues is guaranteed if the three initial assumptions are fulfilled, which results equivalent to require:

$$
\left(\left[\begin{array}{cc}
\mathrm{A} & \mathrm{B} \\
-\mathrm{C} & 0
\end{array}\right],\left[\begin{array}{c}
\mathrm{B} \\
0
\end{array}\right]\right)=\left(\mathrm{A}_{c 1-\mathrm{int}}, \mathrm{B}_{c 1-\mathrm{int}}\right)
$$

As a result, the closed-loop eigenvalues can be arbitrarily placed by a proper choice of the augmented feedback gain vector $\mathrm{K}_{t}=\left[\mathrm{K}-k_{i}\right]$ in a similar way as it was presented for the feedback gain method.

\section{Simulation results}

The control system is simulated using MATLAB/ SIMULINK, where the parameters of EMLS are listed in Table 2.

\section{Open-loop system}

Figure 6 illustrates the rod position without state feedback. Open-loop poles are placed in $99.0454,-99.0454$ and 10.0000. It is clear that the system is unstable.

\section{Closed-loop system with state feedback}

Closed-loop poles are determined at $-10,-15$ and -25 . So, the state feedback gain matrix is obtained as,

$$
\mathrm{K}=[-557.9139,-11.9484,40.0000]
$$

Figure 7 shows the unit step response of the rod position with state feedback.

It is obvious from Fig. 7 that the closed-loop in the steady state is stable, but the rod position error is so high. 
Table 2. Parameters of the levitation system with hollow steel shaft

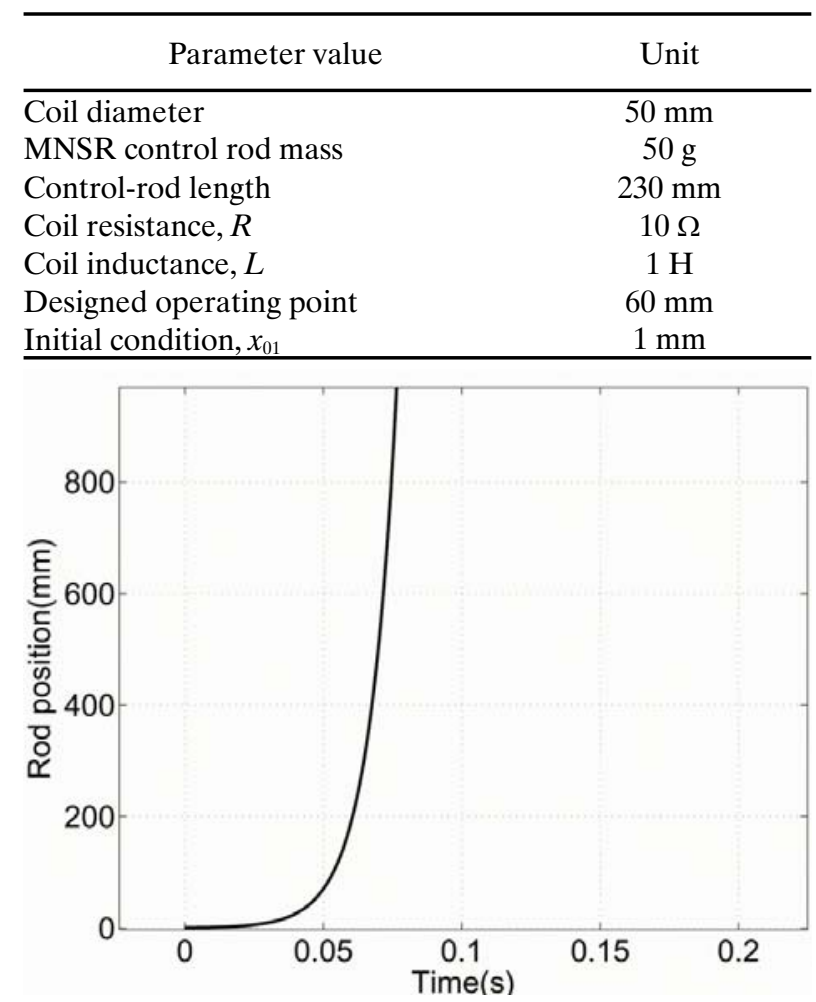

Fig. 6. Open-loop response of the rod position.

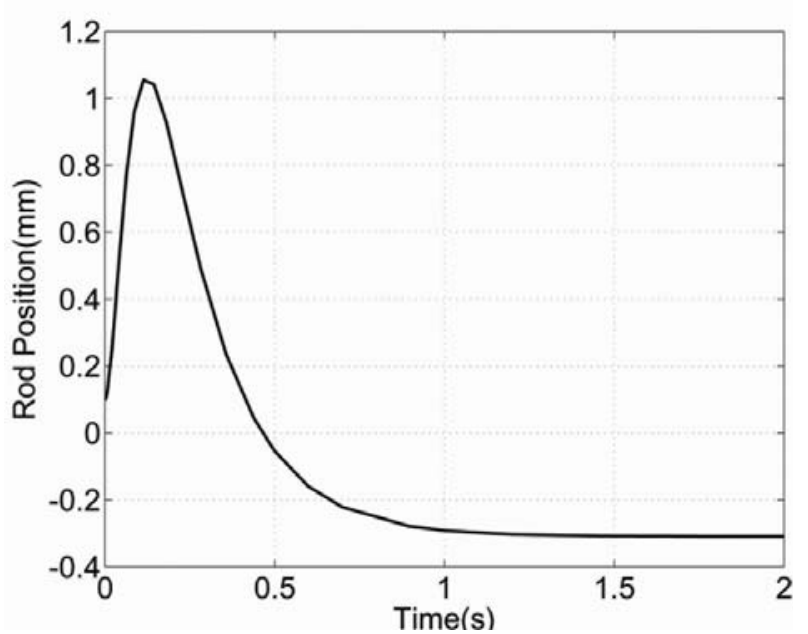

Fig. 7. Closed-loop response of the rod position with state feedback.

\section{Closed-loop system with state feedback and tracking}

Closed-loop poles are determined at $-10,-11,-12$ and -15 . The state feedback gain matrix is obtained as

$$
\mathrm{K}_{t}=[-539.1531,12.0410,38.0000,-22.3504]
$$

Figure 8 shows the step response of the rod position with the state feedback tracking. By according to control the rod speed limit of MNSR, $10.6 \mathrm{~mm} / \mathrm{s}$, step final value considered at $10.6 \mathrm{~mm}$. Fig. 8 shows the control system tracks the control-rod position $10.6 \mathrm{~mm}$ in about $1 \mathrm{~s}$.

To shut down nuclear reactor the control rods must be dropped into the reactor core. Figure 9 shows that

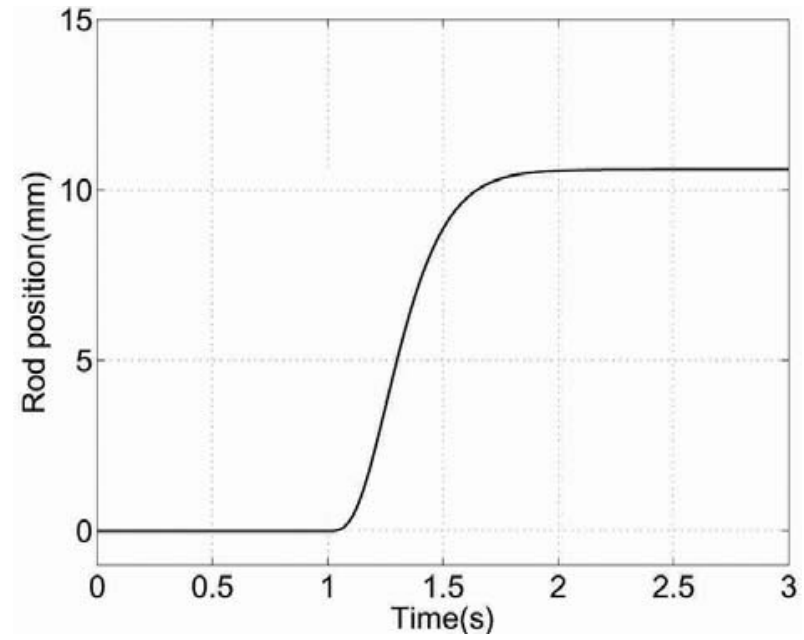

Fig. 8. Closed-loop response of the rod position with state feedback and integral tracking.

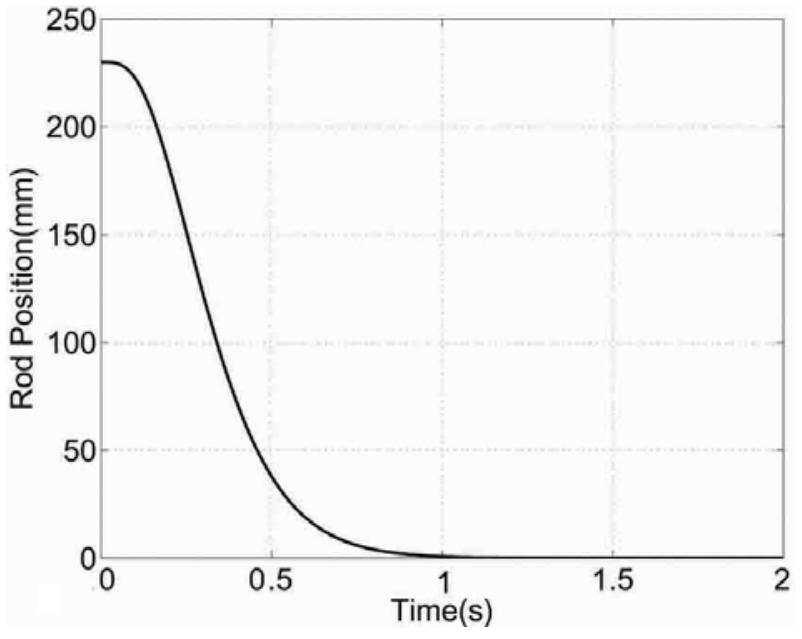

Fig. 9. MNSR control-rod drop.

the MNSR control rod which has been dropped during $1 \mathrm{~s}$ into the core.

Since in nuclear reactor operating conditions, the regulating control-rod movement is in frequent movement to response the power level, we try to model a continuous control-rod positioning.

It is clear from Fig. 10 that EMLS with integral tracking follows the position demand with high per-

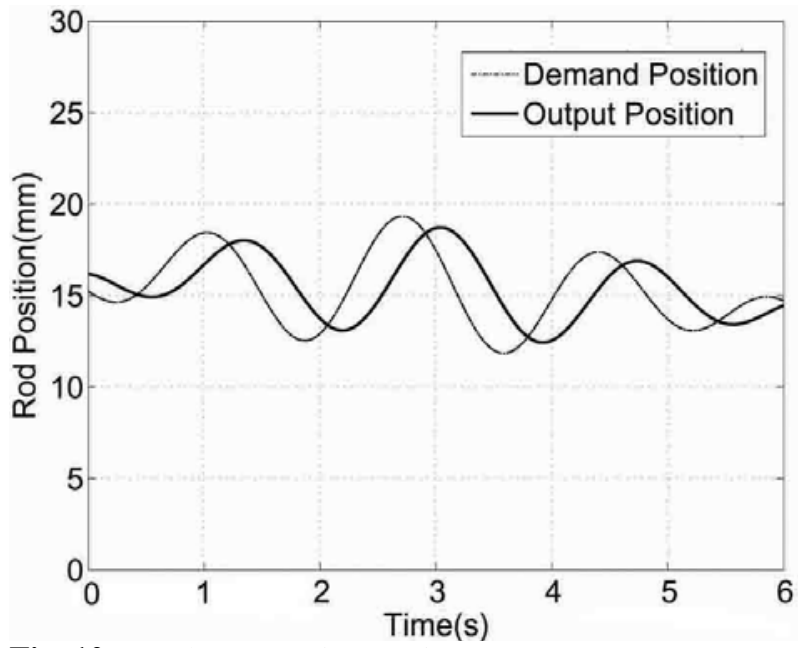

Fig. 10. Continuous rod control. 


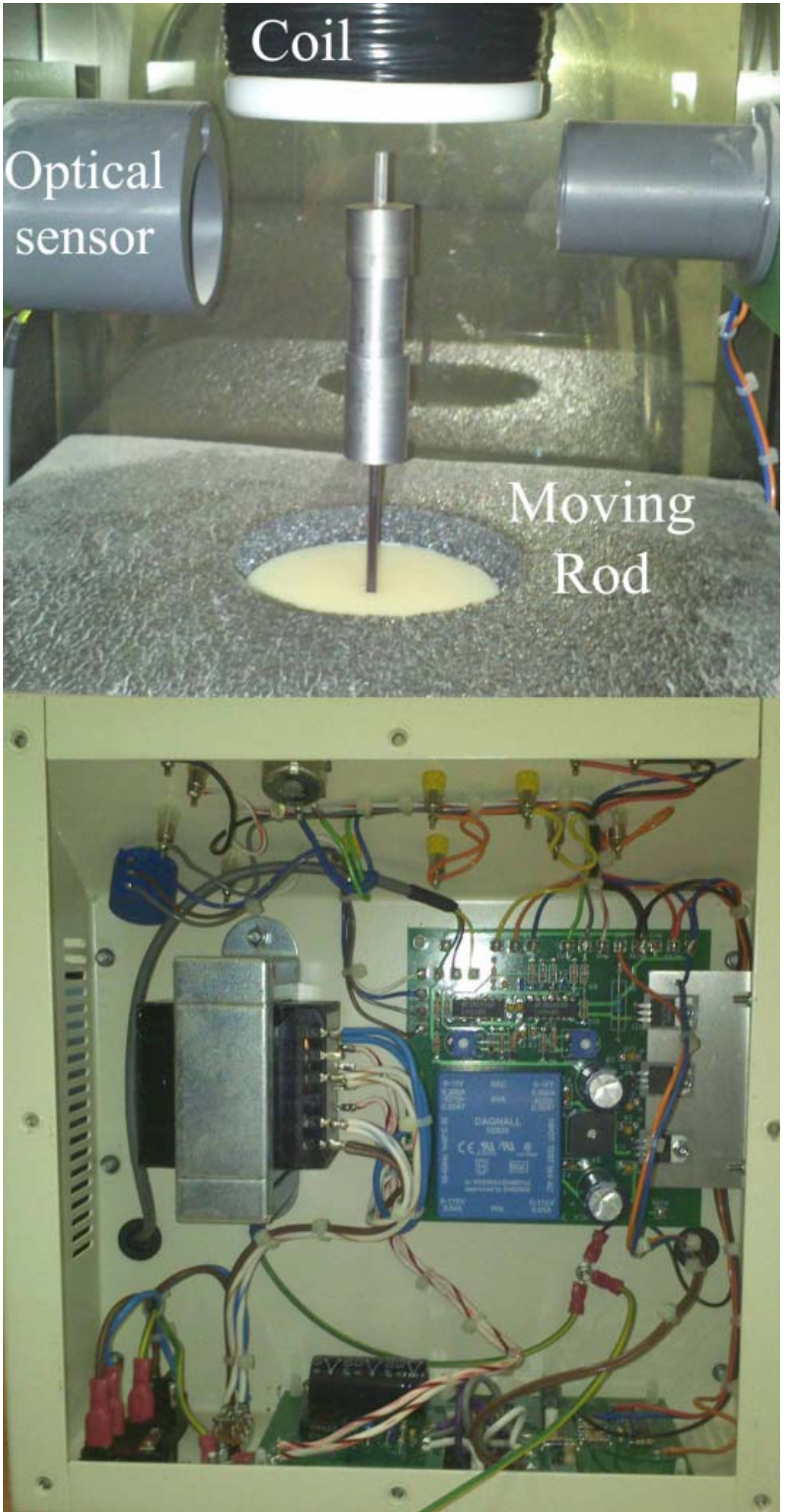

Fig. 11. EMLS laboratory prototype.

formance. A prototype EMLS laboratory set based on the proposed procedures has been built with Table 2 parameters. The prototype is shown in Fig. 11. Because of some dimension limitations, the length of the control rod is made $100 \mathrm{~mm}$.

\section{Conclusion}

Electromagnetic levitation actuator has been applied to MNSR for precision control-rod positioning. The results from the prototype system showed that the proposed method is useful in such a sensitive application. The simulation results show that the closed-loop control system with the state feedback tracking method has a good response time at steady state and transient operation. Thus, this system can be designed to apply in power reactors to control the regulating rods locally.

Acknowledgments. The authors would like to express their appreciation to Aliabad Katoul Islamic Azad University for financial support. Also, the authors wish to thank AKIAU laboratory team who helped on this study, K. Deilam, M. Rahdari, R. Mohammadi, G. Alamshahi.

\section{Nomenclature}

$y(t)$ - hollow steel shaft position (M)

$R$ - winding resistance $(\Omega)$

$M$ - ball mass $(\mathrm{Kg})$

$U(t)$ - input voltage $(\mathrm{V})$

$i(t)$ - winding current (A)

$L$ - winding inductance $(\mathrm{H})$

$g \quad-$ acceleration of gravity $\left(\mathrm{m} / \mathrm{s}^{2}\right)$.

\section{References}

1. Hanliang, B., Wenxiang, Z., \& Duo, D. (2000). Studies on the performance of the hydraulic control rod drive for the NHR-200. Nucl. Eng. Des., 195, 117-121.

2. Yuanqiang, W., Xingzhong, D., Huizhong, Z., \& Zhiyong, H. (2002). Design and tests for the HTR-10 control rod system. Nucl. Eng. Des., 218, 147-154.

3. Takeda, T., \& Tachibana, Y. (2003). Indirect air cooling techniques for control rod drives in the high temperature engineering test reactor. Nucl. Eng. Des., 223, 25-40.

4. Chyou, Y. P., Yu, D. D., \& Chen, Y. N. (2004). Performance validation on the prototype of control rod driving mechanism for the TRR-II project. Nucl. Eng. Des., 227, 195-207.

5. Mousavi Shirazi, S. A., Aghanajafi, C., Sadoughi, S., \& Sharifloo, N. (2010). Design, construction and simulation of a multipurpose system for precision movement of control rods in nuclear reactors. Ann. Nucl. Energy, 37, 1659-1665.

6. Tanaka, A., Futahashi, K., Takanabe, K., Kurimura, C., Kato, J., \& Hara, H. (2008). Development of a 3-D simulation analysis system for PWR control rod drive mechanism. Int. J. Pressure Vessels Pip., 85, 655-661.

7. International Atomic Energy Agency. (1986). Technology and use of low power research reactors. Vienna: IAEA. (IAEA-TECDOC-384).

8. Tabadar, Z., Hadad, K., Nematollahi, M. R., Jabbari, M., Khaleghi, M., \& Hashemi-Tilehnoee, M. (2012). Simulation of a control rod ejection accident in a VVER-1000/V446 using RELAP5/Mod3.2. Ann. Nucl. Energy, 45, 106-114.

9. Ku, C. L., Li, T. H. S., \& Guo, N. R. (2005). Design of a novel fuzzy sliding-mode control for magnetic ball levitation system. J. Intell. Robot. Syst., 42(3), 295-316.

10. Maghsoudlou, A., Barzamini, R., \& Farhani, K. D. (2011). Non-linear control based on feedback linearization for double-electromagnet suspension system. Electron. Electr. Eng., 108(2), 85-90.

11. Ogata, K. (2010). Modern control engineering (5th ed.). Boston: Prentice-Hall. 